\title{
Expectation of a Scientific Breakthrough for Realization of a Sustainable Mobile Society
}

\section{Hideki IBA*}

\author{
Battery Research Division, Toyota Motor Corporation, 1200, Mishyuku, Susono, Shizuoka 410-1193, Japan \\ *Corresponding author: hideki_iba@mail.toyota.co.jp
}

\begin{abstract}
The development of high energy density devices produces a dramatic improvement in the cruising range of electric vehicles and significantly contributes to realizing a sustainable society. In recent years, innovative batteries, such as all-solid battery, metal-air battery and sodium-ion battery, etc., which are estimated to provide a superior battery performance better than the latest lithium-ion battery, are now being given significant attention. Meanwhile, a number of breakthroughs are required in order to achieve practical use of these innovative batteries. In this paper, we summarized the current research approaches of these innovative batteries.
\end{abstract}

(c) The Electrochemical Society of Japan, All rights reserved.

Keywords : All-solid Battery, Solid Electrolyte, Lithium-Air Battery, Sodium-ion Battery

\section{Introduction}

In order to realize a sustainable society, it is important to develop fuel efficient and low emission vehicles, and furthermore, the challenge of zero emission vehicles. Various efforts have been applied for the development of weight saving, engines downsizing and new power-train systems including fuel cells and electric motor drives. Although there were arguments whether fuel cell vehicles, electric vehicles or others are the future power-train candidates, we believe several types of vehicles running on different power sources will coexist. Hybrid vehicles, which combine the efficient control of the engine with motor assist and a regeneration system, was the best answer for getting to the market fast as an eco-friendly vehicle. Today, the sales of hybrid vehicles have been increasing after the PRIUS was introduced into the market in 1997 as the world-first mass-production hybrid vehicle.

Meanwhile, the electric driving range per one charge is not sufficient compared to conventional internal combustion engine vehicles, even installing the state-of-the art lithium ion battery. The plug-in hybrid vehicle is a type of hybrid vehicle with an additional battery capacity and a charging plug from an external power source. We believe that the plug-in hybrid vehicle is the next practical vehicle of maximum electric energy utilization, because we

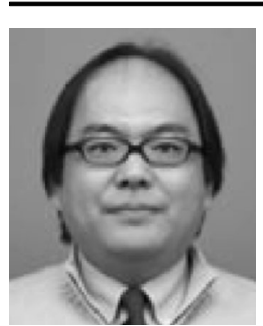

Hideki Iba (General manager of Battery Research Division, Toyota Motor Corporation)

Hideki Iba Received Master degree of engineering from Osaka University and joined Toyota Motor Corporation (TMC) in 1987. He received Doctor of Engineering at School of Engineering, Tohoku Univ in 1997. He developed light metallic automotive parts at Material Engineering Div., TMC in 19871993. He discovered the new Hydrogen Storage Alloy at National Chemical Laboratory for Industry (present, National Institute of Advanced Industrial Science and Technology) in 1993-1996. He planed new leading-edge research projects and coordinated industry-government-academia relationship at R\&D Management Div., TMC in 1996-2008. He has led R\&D of Innovative Batteries at Battery Research Div., TMC in 2008-present. He received The Japan Institute of Metals and Materials Technical Development Award in 1997, and Remarkable Invention Award from Science and Technology Agency in 2000. He specializes in Material Engineering, Nano Technology, and the R\&D management of innovative batteries. coordinate the electric drive range in concert with increasing their battery performances.

\subsection{Expectation for innovative batteries}

In 1925, Sakichi Toyoda, the founder of Toyota Industries Corporation, the company that eventually formed the Toyota Motor Corporation, conducted a public offering for developing a higher energy density battery than that of gasoline. Figure 1 shows the development target of current lithium ion batteries and the theoretical performance of the innovative batteries. Recently, lithium ion batteries are being developed as a power souse of hybrid, plug-in hybrid and electric vehicles, mainly considering safety performance, electric cruising range and costs.

Even though there is no achievement regarding Sakichi's vision, some batteries, such as all-solid and metal-air batteries, have higher theoretical energy densities than the lithium ion battery. Although there have been many ideas for innovative batteries, they are not in practical use for vehicles. This means that there are still many issues to be resolved for using the practical energy sources for vehicle driving. Therefore, we are challenged to resolve the issues of innovative batteries.

\section{Development Approach and Status of All-solid Lithium Battery}

To replace the current lithium ion batteries, we paid attention to the all-solid lithium batteries which used a solid-state electrolyte as the separator, because the features of the inorganic solid-state electrolytes are non-fluidity, wide electrochemical window, and high thermal stability. Based on these features, the all-solid batteries have the potential to minimize the structure of battery cell and pack by simplifying the cooling and safety systems of a battery pack. The performance of the all-solid lithium batteries is getting better with improvements of the interface resistance ${ }^{1}$ and the ion conductivity of the electrolyte over the past several years.

Solid electrolytes have also a long development history. Figure 2 shows the typical properties of an inorganic solid electrolyte. ${ }^{2-7}$ In particular, sulfide electrolytes have high conductivities and comparative stabilities regarding their reduction potential. Additionally, sulfides have a low resistance at the interface between the solid electrolyte materials. Kanno et al. has successfully developed the highest conductivity solid electrolyte, $\mathrm{Li}_{10} \mathrm{GeP}_{2} \mathrm{~S}_{12}$ with $1.2 \times$ 


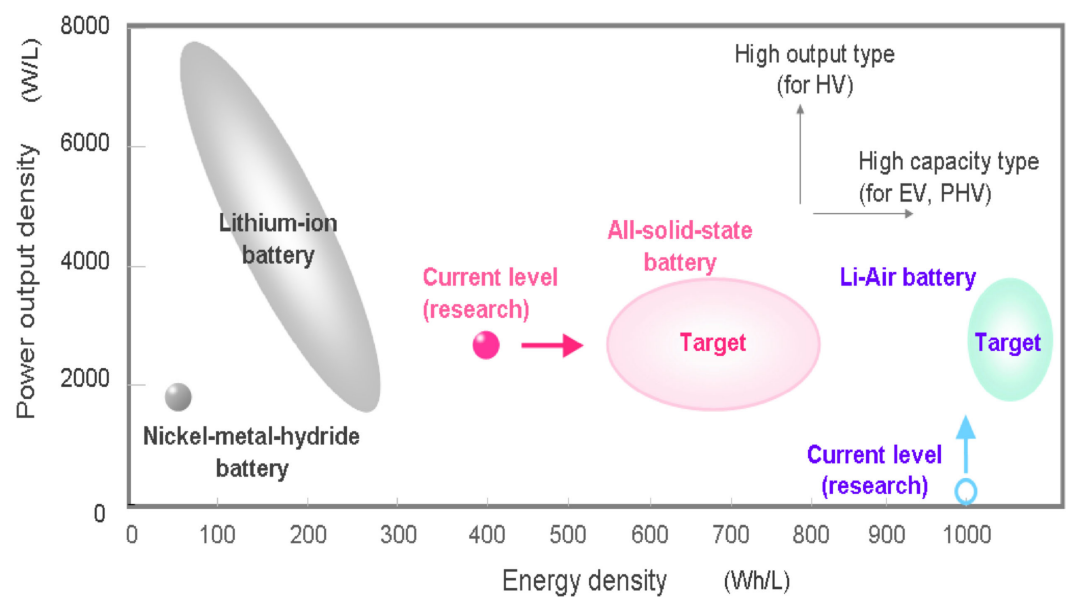

Figure 1. (Color online) Development targets of current lithium ion batteries and the theoretical performance of the innovative batteries.

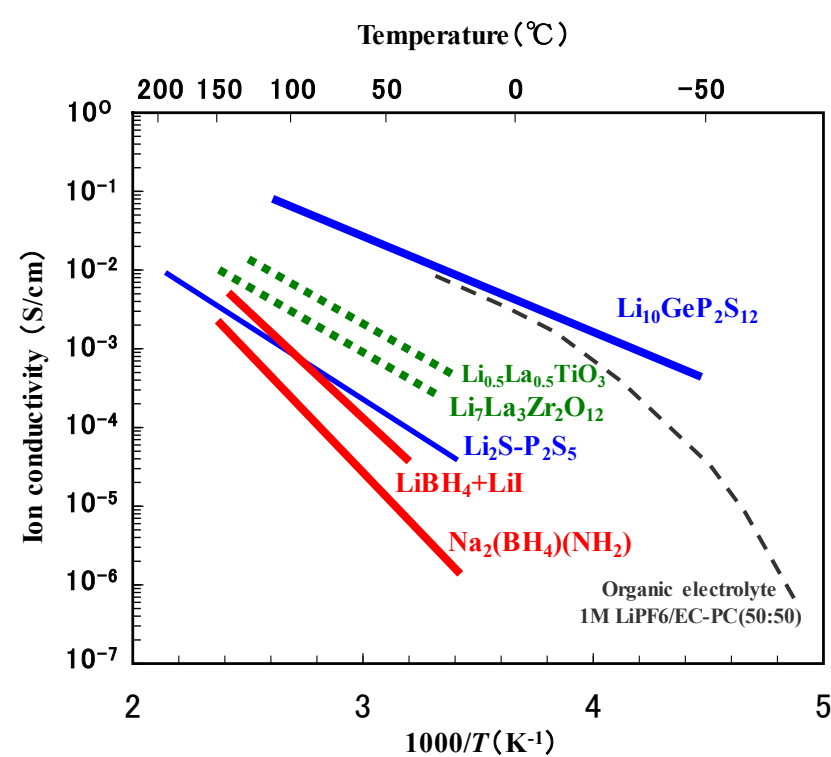

Figure 2. (Color online) Ion conductivity of solid electrolytes.

$10^{-2}(\mathrm{~S} / \mathrm{cm}) @ 25^{\circ} \mathrm{C}$, that had a conductivity comparable to the nonaqueous electrolyte of current lithium ion batteries. ${ }^{8}$ To demonstrate the ability of the all-solid batteries with a sulfide electrolyte, we developed various experimental applications, i.e., scooter, automated guided vehicle and small electric vehicle.

On the other hand, sulfide electrolytes have a problem such that they are unstable in the ambient air. Meanwhile, solid oxide electrolytes are stable in the ambient air, although they do not have a conductivity higher than the sulfide electrolytes. The perovskitetype $\left(\mathrm{ABO}_{3}\right)$ lithium ion conductors, $\mathrm{La}_{(2 / 3-x)} \mathrm{Li}_{3 x} \mathrm{TiO}_{3}$ (LLTO) ${ }^{3}$ and $\mathrm{La}_{(1-x) / 3} \mathrm{Li}_{x} \mathrm{NbO}_{3}$ (LLNO) ${ }^{9}$ are known as super ionic conductors having up to a $10^{-5} \mathrm{~S} / \mathrm{cm}$ conductivity.

The ionic conductivity of the solid electrolyte significantly depends on the bulk structure. However, it is also necessary to consider ionic conduction using defects and grain boundaries. The term "defect" refers to strain caused by ion vacancies (lattice defects) or dislocations. An actual structure contains defects, such as vacancies (lattice defects), dislocations, and voids, as well as grain boundaries. Although these phenomena are also thought to have a major impact on the lithium ion conduction, their characteristics have yet to be fully identified. If bulk single crystals of the solid state electrolyte that exhibit the various crystalline characteristics can be obtained, they can be used to clarify various fundamental aspects of conduction in the solid state electrolyte. Perovskite-type

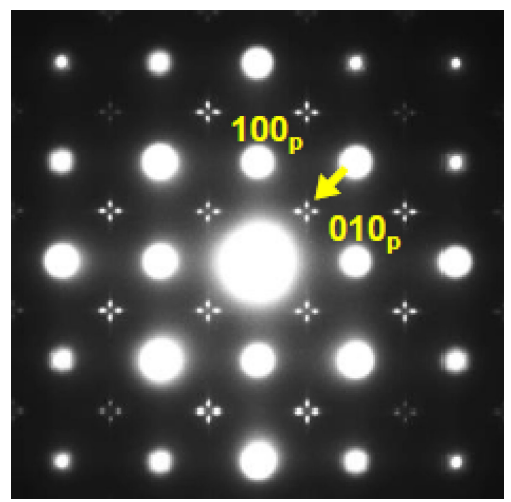

Figure 3. (Color online) SAED patterns of LLNO [001]p zone axis. Arrow denotes the splitting of the spots at $(\mathrm{h} / 2 \mathrm{k} / 20)$.

single crystals, LLNO, were grown by a unidirectional solidification method $^{10}$ and the ion conductivity and microstructure investigated.

The $\mathrm{Li}$ ion conductivity of LLNO varies depending on the $\mathrm{Li}$ fraction $x$. The maximum value of the single crystal LLNO was $1.9 \times 10^{-4} \mathrm{~S} / \mathrm{cm}$ at $x=0.075,{ }^{10}$ which is higher than the maximum value of the polycrystal LLNO $\left(4.7 \times 10^{-5} \mathrm{~S} / \mathrm{cm}\right.$ at $\left.x=0.1\right) .{ }^{9}$

The microstructure of perovskite-type single crystals, LLNO, was investigated by TEM. ${ }^{11}$ Figure 3 shows selected area electron diffraction (SAED) patterns for $\mathrm{La}_{(1-x) / 3} \mathrm{Li}_{x} \mathrm{NbO}_{3}$ with the composition $x=0.04$ projected along the zone axe [001]p (p refers to the basic perovskite unit cell). The images show that the additional superlattice reflections at $(\mathrm{h} / 2 \mathrm{k} / 2 \mathrm{0})(\mathrm{h}, \mathrm{k}=$ odd numbers) and the $(\mathrm{h} / 2 \mathrm{k} / 2 \mathrm{0})$ reflections are split into four spots in the form of cross that are aligned parallel to $g(100) p$ and $g(010) p$. Figure 4(a) and (b) shows high-angle annular dark-field (HAADF) imaging taken along the [110]p zone axes of $\mathrm{La}_{0.32} \mathrm{Li}_{0.04} \mathrm{NbO}_{3}$. A modulated ordering of the lanthanum, oxygen, and vacancy column in the A1 layers along the [110]p direction was observed. The modulated column-ordering is more apparent in the intensity-scan profiles in Fig. 4(c). A sinusoidal variation in the A1 column intensities, directly related to the La occupancies of each column along the [110]p zone axis, is evident in $\mathrm{La}_{0.32} \mathrm{Li}_{0.04} \mathrm{NbO}_{3}$, with super-periodicities of either $7 \mathrm{~d}(110) \mathrm{p}$ or $7.5 \mathrm{~d}(110) \mathrm{p}$. The origin of the splitting of the $(\mathrm{h} / 2 \mathrm{k} / 20)$ reflections into the four spots in the [001]p SAED pattern was attributed to the formation of the modulated ordering column in the A1 layers along the [110]p direction.

We expect that the rule factor of ion conductivity will be clarified by investigating the relations between the Li-ion conductivity and microstructure of $\mathrm{La}_{(1-x) / 3} \mathrm{Li}_{x} \mathrm{NbO}_{3}$ with various $\mathrm{Li}$ contents. 


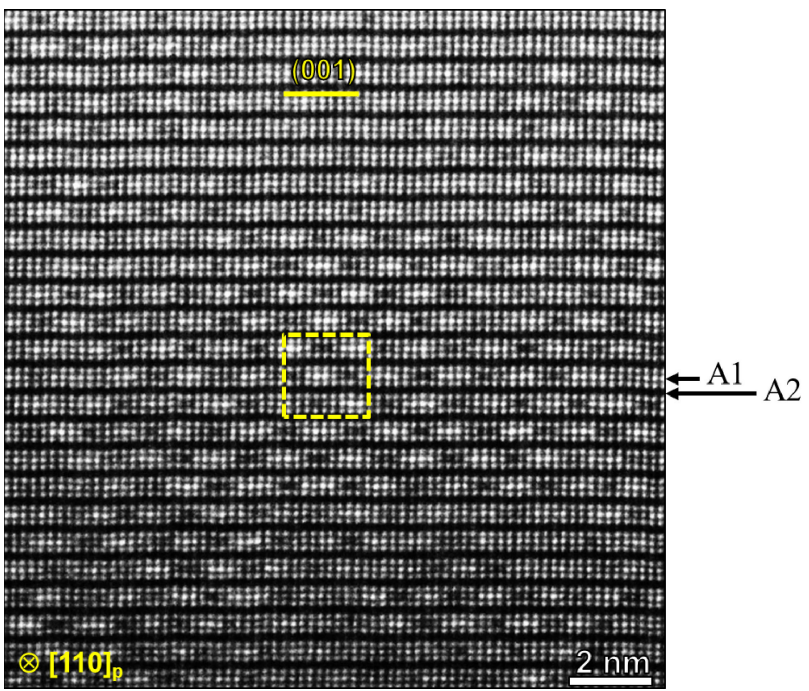

(a) Medium-magnification HAADF micrograph

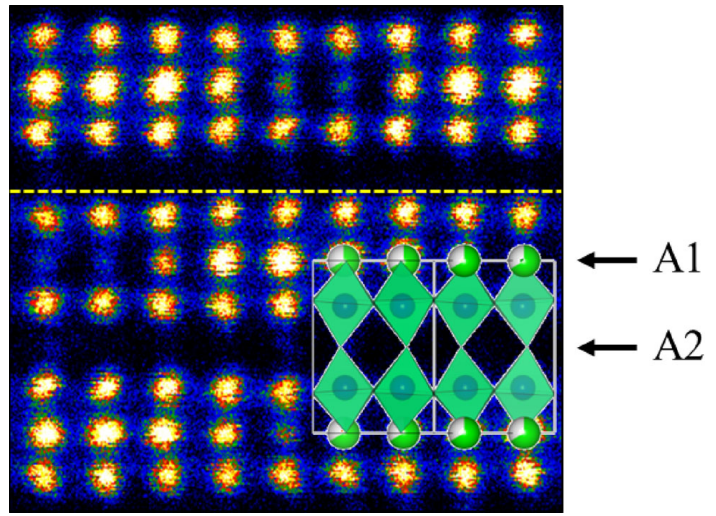

(b) High-magnification HAADF micrograph

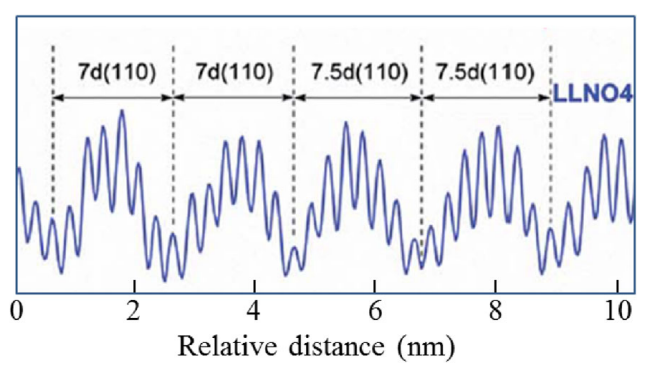

(c) Intensity-scan profiles taken from the A1 column

Figure 4. (Color online) HADDF image of LLNO along [110]p zone axes.

\section{Li-Air Battery}

The Li-air battery is a promising candidate to realize such next generation batteries, because oxygen gas as a positive electrode material can be continuously supplied from outside of the battery, and furthermore, the lithium metal with the high theoretical capacity of $3860 \mathrm{mAh} / \mathrm{g}$ can be fully utilized (Fig. 5).

We have investigated the rechargeability and cyclability of Li-air batteries to be utilized as a secondary battery. By using a carbonatebased electrolyte (propylene carbonate: PC), the same as in previous reports, ${ }^{12}$ it was observed that the discharge and charge voltages were $2.6 \mathrm{~V}$ and $4.0 \mathrm{~V}$, respectively, therefore, a large voltage gap of $1.4 \mathrm{~V}$ was produced, resulting in a lower energy efficiency of the $\mathrm{Li}$ Air battery (Fig. 6). It was believed that the $\mathrm{Li}_{-} \mathrm{O}_{2}$ batteries with nonaqueous electrolytes would behave as secondary ones. However, we found that unfavorable reaction products on the positive
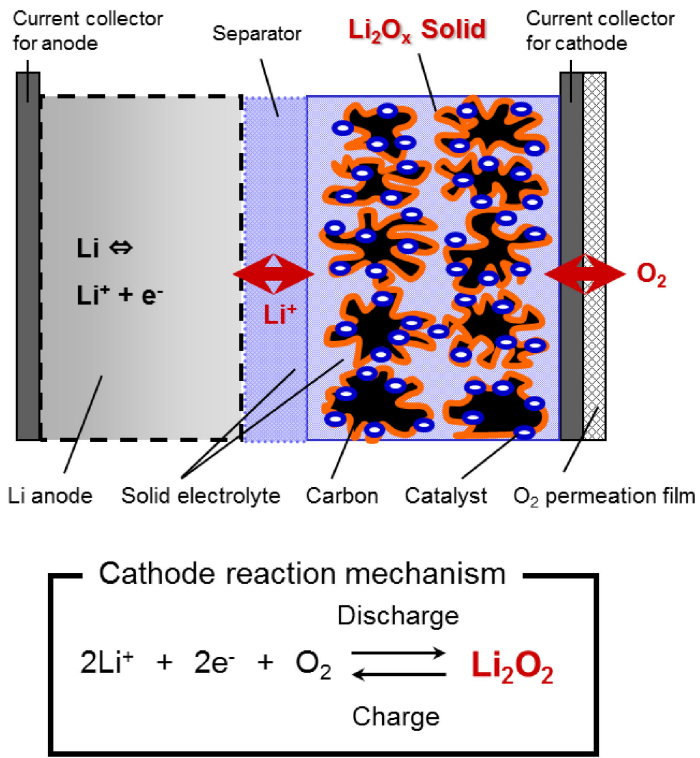

Figure 5. (Color online) Schematic diagram of the rechargeable nonaqueous Li-Air battery.

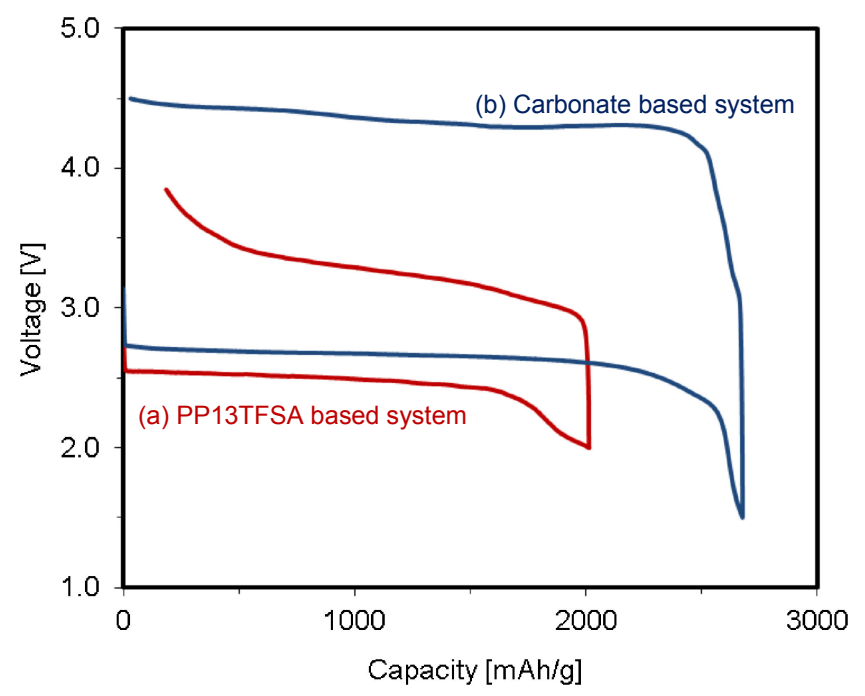

Figure 6. (Color online) Initial discharge and charge curves of the (a) PP13TFSA based and (b) typical carbonate based $\mathrm{Li}^{-} \mathrm{O}_{2}$ cells at $25^{\circ} \mathrm{C}$. Applied current densities for discharging and charging were 0.02 and $0.01 \mathrm{~mA} \mathrm{~cm}^{-2}$, respectively.

electrode were obtained during the discharging and charging. ${ }^{13}$ On the other hand, by using the $N$-methyl- $N$-propylpiperidinium bis(trifluoromethansulfonyl) amide (PP13TFSA) ionic liquid as the electrolyte, not only a low charging voltage of around $3.3 \mathrm{~V}$, but also a small voltage gap of about $0.75 \mathrm{~V}$ were achieved. ${ }^{14}$ Based on our analytical results, the positive electrode reaction mechanisms of the PP13TFSA and PC based $\mathrm{Li}_{-} \mathrm{O}_{2}$ batteries are summarized in Fig. $7 .{ }^{15}$ Route (i) is the originally expected reaction route at the positive electrode. Route (ii) denotes the conventional positive electrode reaction route including the PC-based system. The last route (iii) represents the newly revised route including the PP13TFSA-based system. Most organic solvents comprised of propylene carbonate (PC) were electrochemically and chemically vulnerable to radical species formation. Therefore, as in the conventional route (ii), the decomposition of the electrolyte solvent occurred and the decomposed species, such as lithium alkylcarbonate, were precipitated on a discharged positive electrode, 


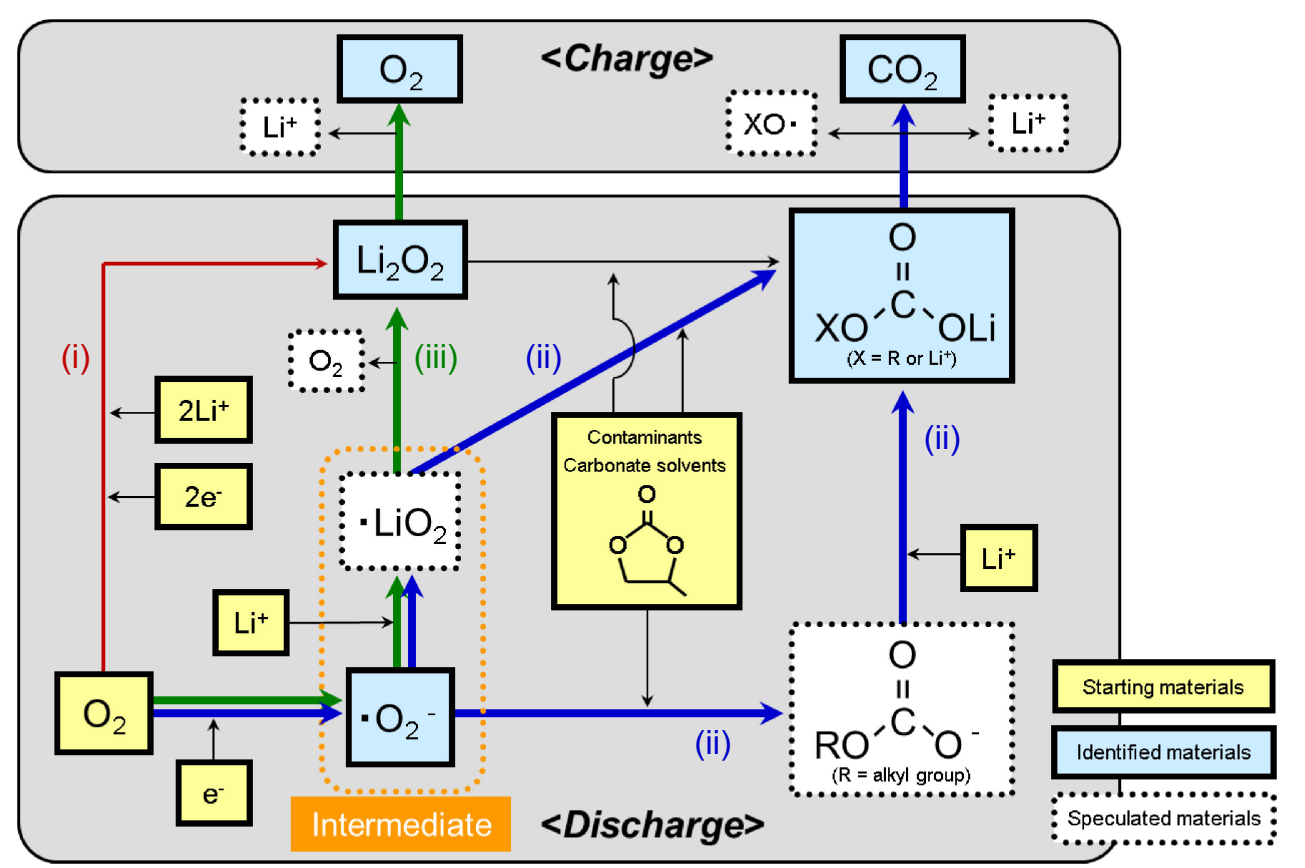

Figure 7. (Color online) Reaction route map of nonaqueous $\mathrm{Li}_{-} \mathrm{O}_{2}$ batteries for mechanistic understanding.

resulting in $\mathrm{CO}_{2}$ generation after recharging. On the other hand, the PP13TFSA ionic liquid was highly stable against the radical species. As a consequence, the solvation of radical species prevented the electrolyte solvents from being decomposed, and then converted the conventional reaction route (ii) into the revised one (iii). Above all, the stabilization of the $\mathrm{O}_{2}$ radical species was an important key to suppressing the electrolyte decomposition and then to determine the discharge reaction process and the subsequent charging process at the positive electrode. Thus, it was concluded that our proposed PP13TFSA ionic liquid was a key component to produce the desirable positive electrode reaction, that is, $\mathrm{Li}_{2} \mathrm{O}_{2}$ formation.

Carbon must play an important role in storing the deposits, such as $\mathrm{Li}_{2} \mathrm{O}_{2}$, in the positive electrode, because it has a large surface area and high pore volume attributed to micro and meso scaled pores. According to previous reports, the discharge capacities of Li-air batteries strongly depended on the porosities of the carbon powder, such as surface area and meso pore volume. ${ }^{16}$ This result indicates that the discharge products would be preferentially stored in the meso-sized region of the carbon pores. On the other hand, in our preliminary study, it was observed that the discharge products of $10-20 \mathrm{~nm}$ primary particle size were agglomerated in a discharged positive electrode, ${ }^{13}$ and furthermore, micro-meter-sized aggregates were formed in a comparably high capacity positive electrode. Since the discharge products, such as $\mathrm{Li}_{2} \mathrm{O}_{2}$, are generally insulating, the large-sized aggregates will be difficult to be decomposed during charging. The size of the discharge products has to be controlled to improve the charging properties of the batteries. Therefore, we have discussed how the carbon active site influenced the morphology of the positive electrode deposits during the discharge of Li-air batteries. ${ }^{17,18}$ Figure 8 shows AFM image after a slight discharge reaction of Li-air batteries. HOPG (Highly Ordered Pyrolytic Graphite) was used as the positive electrode. In this image, no discharge deposits $\left(\mathrm{Li}_{2} \mathrm{O}_{2}\right)$ were found on the clear steps but were found on the geometrically smooth area. We postulate that there is actually a monolayer or bilayer on this smooth area and this area has a much higher reaction activity than other area. Figure 9 shows a cyclic voltammogram for two kinds of HOPGs of different heat treatments, and used as the working electrode. This figure shows that the lower heat-treated HOPG electrode has a higher reaction current. This means that the lower heat-treated HOPG has more defects and steps and is more reactive. In this way, defects and steps
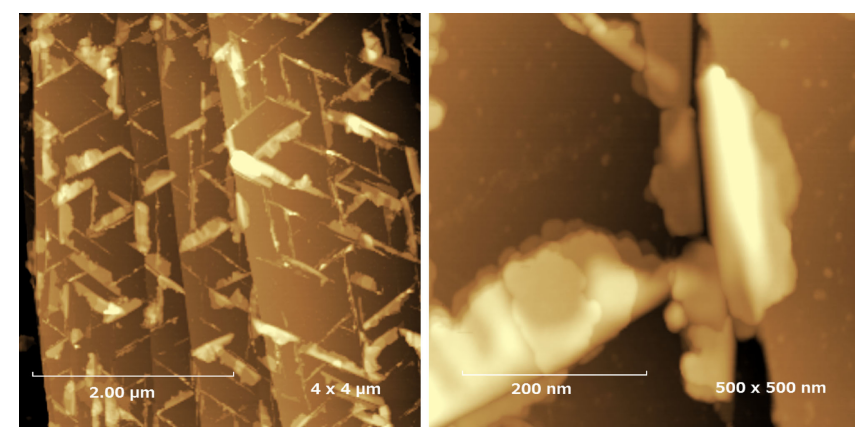

Figure 8. (Color online) AFM images of ths surface of HOPG electrode after a minimal discharge reaction of lithium air secondary battery.
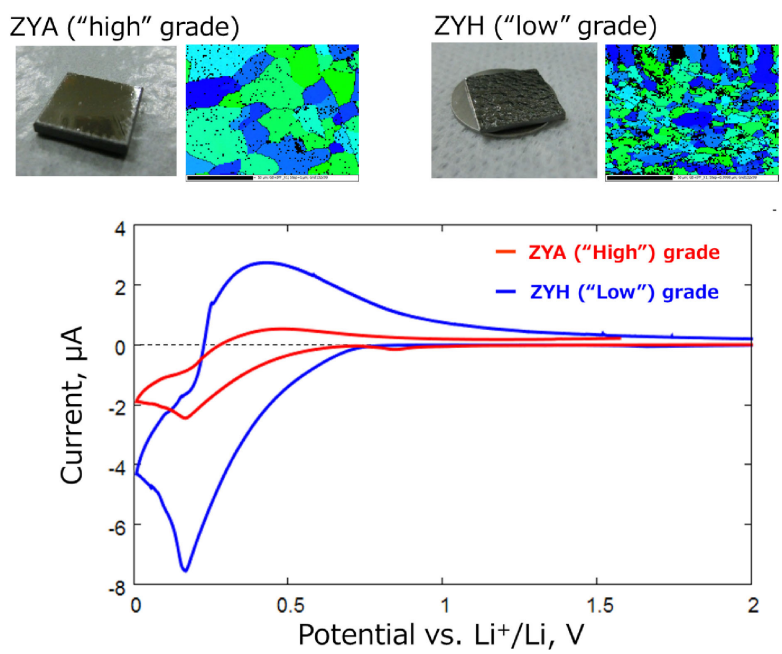

Figure 9. (Color online) Cyclic voltammograms of two kinds of HOPG electrodes. Scan rate was $0.01 \mathrm{mV} / \mathrm{sec}$ and the applied temperature was $25^{\circ} \mathrm{C}$.

have a big impact on the electrochemical properties. Therefore, they are useful as an index to develop the optimum carbon materials. However, it is very difficult to determine their quantity, thus we 


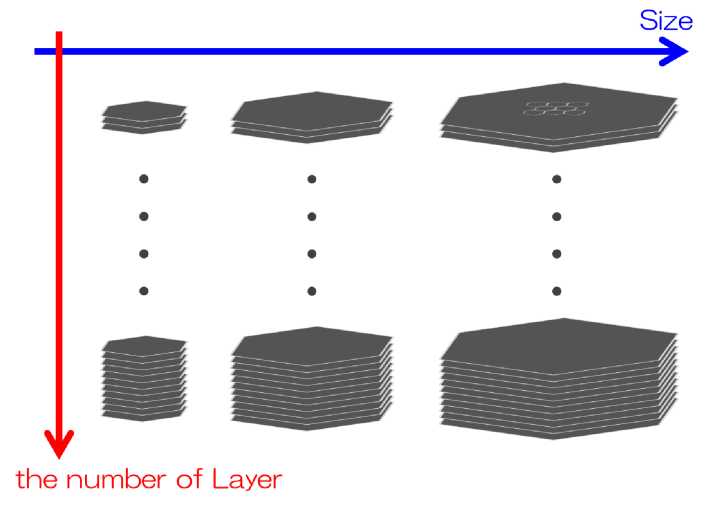

Figure 10. (Color online) Schematic diagram of the number of layers and the crystallite size of graphite.

cannot utilize them as an index. "To determine quantity" means that the number of layers and the size of the crystallites as shown in Fig. 10 can be quantitatively measured. For the purpose of finding the optimum carbon materials, it is very important to study how much they have an impact on the electrochemical properties. I now hope that the development of carbon materials will proceed to utilize such a new index.

\section{Sodium-ion Battery}

In recent years, many researchers have developed the sodium-ion batteries, which are promising substitutes for lithium-ion batteries. The advantage of sodium-ion batteries is not only the abundant natural resources, but also the possibility of high performance batteries compared to the lithium system because of the wide selectivity of the sodium compounds. In fact, novel positive electrode materials were discovered for the sodium-ion batteries in recent years. Nose et al. successfully discovered the novel positive electrode material of $\mathrm{Na}_{4} \mathrm{Co}_{3}\left(\mathrm{PO}_{4}\right)_{2} \mathrm{P}_{2} \mathrm{O}_{7}$ as shown in Fig. 11 having high voltage and high rate capabilities. ${ }^{19}$ The electrochemical reaction of $\mathrm{Na}_{4} \mathrm{Co}_{3}\left(\mathrm{PO}_{4}\right)_{2} \mathrm{P}_{2} \mathrm{O}_{7}$ involved the multi-redox couples in the highest potential region over $4 \mathrm{~V}$ vs. $\mathrm{Na} / \mathrm{Na}^{+}$among any reported sodium positive electrode materials as shown in Fig. 12. The reversible capacity of $\mathrm{Na}_{4} \mathrm{Co}_{3}\left(\mathrm{PO}_{4}\right)_{2} \mathrm{P}_{2} \mathrm{O}_{7}$ reached ca. $80 \mathrm{mAh} / \mathrm{g}$ even at the high-rate condition of $25 \mathrm{C}(4250 \mathrm{~mA} / \mathrm{g})$. As shown in the crystal structure of $\mathrm{Na}_{4} \mathrm{Co}_{3}\left(\mathrm{PO}_{4}\right)_{2} \mathrm{P}_{2} \mathrm{O}_{7}$, four types of $\mathrm{Na}^{+}$sites are located in the three-dimensional ion channel, therefore, this unique crystal structure would have the advantage of ion diffusivity that affects the rate capability. It was discovered that $\mathrm{Na}_{4} \mathrm{Co}_{3}\left(\mathrm{PO}_{4}\right)_{2}$ $\mathrm{P}_{2} \mathrm{O}_{7}$ had redox couples in a high potential region and operated at a high current density, however, the reversible capacity was still low compared to the conventional positive electrode materials of lithium-ion batteries. In order to increase the reversible capacity of $\mathrm{Na}_{4} \mathrm{Co}_{3}\left(\mathrm{PO}_{4}\right)_{2} \mathrm{P}_{2} \mathrm{O}_{7}$, the Co transition metal was partly substituted for $\mathrm{Mn}$ and $\mathrm{Ni}$. The substitution of $\mathrm{Mn}$ and Ni suppressed the lattice volume change during the $\mathrm{Na}^{+}$extraction process. As a result, the reversible capacity of $\mathrm{Na}_{4} \mathrm{Co}_{3-x} \mathrm{M}_{x}\left(\mathrm{PO}_{4}\right)_{2} \mathrm{P}_{2} \mathrm{O}_{7}(\mathrm{M}=\mathrm{Mn}, \mathrm{Ni})$ reached more than $100 \mathrm{mAh} / \mathrm{g} .{ }^{20}$ These findings suggest that the $\mathrm{Na}_{4} \mathrm{M}_{3}\left(\mathrm{PO}_{4}\right)_{2} \mathrm{P}_{2} \mathrm{O}_{7}$ can be one of the good candidate materials for the positive electrode materials with high voltage, high rate, large capacity and good cyclability for sodium-ion batteries.

Furthermore, attractive positive electrode materials for sodiumion batteries have been developed. ${ }^{21,22}$ However, only a few negative electrode and electrolyte materials have been reported so far. ${ }^{23,24}$ Although the sodium-ion batteries should overcome several hurdles for practical use, it is expected that the research and development about sodium-ion batteries would produce a new potential as innovative batteries going beyond lithium-ion batteries.

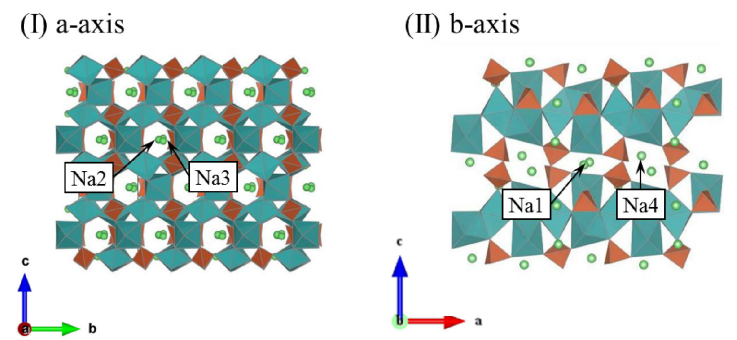

(III) c-axis

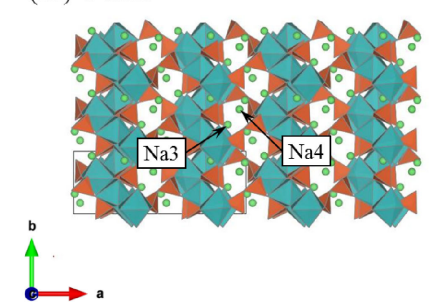

Figure 11. (Color online) Crystal structure of $\mathrm{Na}_{4} \mathrm{Co}_{3}\left(\mathrm{PO}_{4}\right)_{2} \mathrm{P}_{2} \mathrm{O}_{7}$.

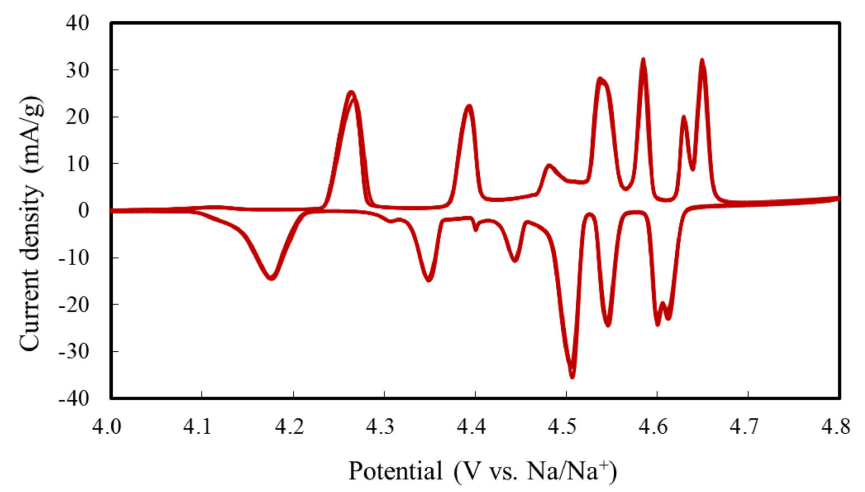

Figure 12. (Color online) Cyclic voltammogram of $\mathrm{Na}_{4} \mathrm{Co}_{3}$ $\left(\mathrm{PO}_{4}\right)_{2} \mathrm{P}_{2} \mathrm{O}_{7}$ at the scan rate of $0.01 \mathrm{mV} / \mathrm{s}$.

As a new methodology for the search of materials, which possess the specified properties desired by industry, "Materials Informatics" is receiving a lot of attention. This data-driven method inductively gains knowledge from massive correlation data, including structural descriptors and properties of materials from simulations and experiments. Therefore, the discovery of knowledge is expected to lead to shortening the development time for the synthesis of practical sodium-ion materials in the future.

\section{Conclusion}

The all-solid battery, lithium-air battery, and the sodium-ion battery are expected, to be the most likely candidates of replacing the current lithium ion batteries and enhancing the electric driving range of plug-in hybrid vehicles. However, as already described, there are many fundamental issues realizing new innovative batteries. We feel strongly that basic approaches, such as nanostructure analysis technologies and material informatics, are key technologies to reach our goal of practical and innovative batteries.

\section{Acknowledgment}

We thank X. Gao, A. J. Fisher, T. Kimura, Y. H. Ikuhara, H. Moriwake, A. Kuwabara, and Y. Ikuhara of the Nanostructures Research Laboratory, Japan Fine Ceramics Center for LLNO observation by TEM. We also thank Y. Fujiwara, and K. Hoshikawa of Shinshu University for the single crystal LLNO preparation. 


\section{References}

1. N. Ohta, K. Takada, I. Sakaguchi, L. Q. Zhang, R. Z. Ma, K. Fukuda, M. Osada, and T. Sasaki, Electrochem. Commun., 9, 1486 (2007).

2. Y. Inaguma, L. Chen, M. Itoh, T. Nakamura, T. Uchida, H. Ikuta, and M. Wakihara, Solid State Commun., 86, 689 (1993).

3. S. Stramare, V. Thangadurai, and W. Weppner, Chem. Mater, 15, 3974 (2003).

4. R. Kanno and M. Murayama, J. Electrochem. Soc., 148, A742 (2001).

5. F. Mizuno, A. Hayashi, K. Tadanaga, and M. Tatsumisago, Adv. Mater., 17, 918 (2005).

6. H. Maekawa, M. Matsuo, H. Takamura, M. Ando, Y. Noda, T. Karahashi, and S. Orimo, J. Am. Chem. Soc., 131, 894 (2009).

7. M. Matsuo, S. Kuromoto, T. Sato, H. Oguchi, H. Takamura, and S. Orimo, Appl. Phys. Lett., 100, 203904 (2012).

8. N. Kamaya, K. Homma, Y. Yamakawa, M. Hirayama, R. Kanno, M. Yonemura, T. Kamiyama, Y. Kato, S. Hama, K. Kawamoto, and A. Mitsui, Nat. Mater., 10, 682 (2011).

9. Y. Kawakami, H. Ikuta, and M. Wakihara, J. Solid State Electrochem., 2, 206 (1998).

10. Y. Fujiwara, K. Kohama, and K. Hoshikawa, 39th International Conference and Expo on Advanced Ceramics and Composites, Abstr., p. 124 (2015).

11. X. Gao, C. A. J. Fisher, Y. H. Ikuhara, Y. Fujiwara, S. Kobayashi, H. Moriwake, A. Kuwabara, K. Hoshikawa, K. Kohama, H. Iba, and Y. Ikuhara, J. Mater. Chem., (2015).

12. T. Ogasawara, A. Debart, M. Holzapfel, P. Novak, and P. G. Bruce, J. Am. Chem.
Soc., 128, 1390 (2006).

13. F. Mizuno, S. Nakanishi, Y. Kotani, S. Yokoishi, and H. Iba, Electrochemistry, 78, 403 (2010).

14. F. Mizuno, S. Nakanishi, A. Shirasawa, K. Takechi, T. Shiga, H. Nishikoori, and H. Iba, Electrochemistry, 79, 876 (2011).

15. F. Mizuno, K. Takechi, S. Higashi, T. Shiga, T. Shiotsuki, N. Takazawa, Y. Sakurabayashi, S. Okazaki, I. Nitta, T. Kodama, H. Nakamoto, H. Nishikoori, S. Nakanishi, Y. Kotani, and H. Iba, J. Power Sources, 228, 47 (2013).

16. T. Kuboki, T. Okuyama, T. Ohsaki, and T. Takami, J. Power Sources, 146, 766 (2005).

17. S. Nakanishi, F. Mizuno, K. Nobuhara, T. Abe, and H. Iba, Carbon, 50, 4794 (2012).

18. S. Nakanishi, F. Mizuno, T. Abe, and H. Iba, Electrochemistry, 80, 783 (2012).

19. M. Nose, H. Nakayama, K. Nobuhara, H. Yamaguchi, S. Nakanishi, and H. Iba, J. Power Sources, 234, 175 (2013).

20. M. Nose, S. Shiotani, H. Nakayama, K. Nobuhara, S. Nakanishi, and H. Iba, Electrochem. Commun., 34, 266 (2013).

21. P. Barpanda, G. Oyama, S. Nishimura, S. Chung, and A. Yamada, Nat. Commun., 5, 4358 (2014).

22. N. Yabuuchi, M. Kajiyama, J. Iwatate, H. Nishikawa, S. Hitomi, R. Okuyama, R. Usui, Y. Yamada, and S. Komaba, Nat. Mater, 11, 512 (2012).

23. H. Nakayama, M. Nose, S. Nakanishi, and H. Iba, J. Power Sources, 287, 158 (2015).

24. A. Hayashi, K. Noi, A. Sakuda, and M. Tatsumisago, Nat. Commun., 3, 856 (2012). 